\title{
REESTRUTURAÇÃO PRODUTIVA E DIVISÃO SEXUAL DO TRABALHO: REFLEXÕES SOBRE O TRABALHO FEMININO CONTEMPORÂNEO ${ }^{1}$
}

\author{
Nilo Silva Pereira Netto ${ }^{2}$ \\ e Nanci Stancki da Luz ${ }^{3}$
}

\begin{abstract}
Resumo
0 texto apresenta uma reflexão sobre a categoria marxista do trabalho e as consequências dessa teoria para compreensão do trabalho feminino. Discute 0 trabalho feminino contemporâneo, notadamente a partir do advento da reestruturação produtiva, episódio fundamental para gerenciamento da crise estrutural do capital. Encerra considerando a importância da reflexão a respeito do trabalho e a divisão sexual do trabalho para compreensão da sociabilidade capitalista contemporânea.
\end{abstract}

Palavras-chave: Mundo do trabalho. Trabalho feminino. Divisão sexual do trabalho. Reestruturação produtiva.

\footnotetext{
${ }^{1} 0$ presente texto é parte da dissertação de mestrado defendida no Programa de Pós-Graduação em Tecnologia da Universidade Tecnológica Federal do Paraná (UTFPR), linha de Tecnologia e Trabalho, intitulada "Mundialização do capital: a divisão sócio-sexual do trabalho das operadoras de checkout".

${ }^{2}$ Mestre em tecnologia pelo Programa de Pós-Graduação em Tecnologia da Universidade Tecnológica Federal do Paraná (UTFPR).nilonetto@gmail.com

3 Professora da Universidade Tecnológica Federal do Paraná (UTFPR). Doutora em Política Científica e Tecnológica pela UNICAMP.nancist@terra.com.br
} 


\title{
Productive Reorganization and Sexual DIVISION OF THE LABOUR: REFLECTIONS ABOUT THE CONTEMPORARY WOMEN WORK
}

\begin{abstract}
The text brings a reflection about the Marxist category of work and the consequences of this theory for the comprehension of women's work. It discusses the contemporary feminine work, notably from the advent of productive restructuring, an essential episode for managing structural crisis of capital. It ends by considering the importance of reflection about work and the sexual division of labor for the understanding of contemporary capitalist sociality.
\end{abstract}

Keywords: World of labor. Feminine work. Sexual division of the labor. Productive reorganization.

\section{INTRODUÇÃO}

presente texto reflete sobre o trabalho feminino contemporâneo, notadamente a partir do advento da reestruturação produtiva, episódio fundamental de gerenciamento da crise estrutural do capital que engendra no campo epistemológico o decreto do fim do trabalho ou da centralidade dessa categoria de análise.

Em contrariedade às teses finalistas sobre 0 trabalho ${ }^{4}$, apresentamos no primeiro momento do texto o arcabouço categorial marxista acerca da categoria trabalho e os desdobramentos necessários dessa teoria para compreensão do trabalho feminino e da sociabilidade capitalista hodierna. Na continuidade, traçamos um quadro da configuração do trabalho feminino no contexto da reestruturação produtiva, apresentando a divisão sexual do trabalho como

\footnotetext{
${ }^{4}$ Nas últimas décadas temos visto a literatura no campo sociológico se defrontar entre aqueles e aquelas que vociferam o fim do trabalho, ou a perda da centralidade do trabalho, e os que afirmam sua permanência nos marcos da sociedade de classes. É o caso em que 0 pensamento contemporâneo passa a anunciar em diversas vias o questionamento do trabalho e, consequentemente, o papel da classe trabalhadora na atualidade social (ANTUNES, 2006; TUMOL0, 1998). Segundo Mauro Luis Iasi (2006), um dos traços mais marcantes do pensamento corrente tem sido colocar em dúvida a possibilidade de as classes sociais se converterem nas bases reais para a formação de uma identidade e ação coletiva. Para Iasi essa indagação orientou toda uma geração de pensadores, desde Hanna Arendt (2000) e Jürgen Habermas (1990 e 1983), passando por Daherendorf (1982) e Bell (1977), até Claus Offe (1987) e André Gorz (1987).
} 
dimensão importante de análise, que permite ressaltar a permanência do trabalho - complexificado, precarizado, degradado para as maiorias, jamais desaparecido - na contemporaneidade do capital.

\section{Trabalho E Divisão SEXUAL DO TRABAlHo}

$\mathrm{Na}$ atualidade, a categoria trabalho pode ser compreendia como um termo altamente polissêmico (FRIGOTT0, 2009) e por isso consideramos necessário expor e ressaltar nossa compreensão acerca da mesma.

Estamos compreendendo o trabalho, nos termos de Lukács, enquanto categoria fundante do ser social. Conforme Marx (2003), é necessário considerar 0 processo de trabalho a parte de qualquer estrutura social determinada primeiramente, pois este, ao produzir valores de uso, não mudará sua natureza geral por beneficiar o capitalista ou estar sob seu controle.

Nesse sentido, o trabalho na perspectiva marxiana é, antes de tudo, um processo no qual participam o ser humano e a natureza, em que o humano com sua própria ação impulsiona, regula e controla seu intercâmbio material com a natureza.

Entretanto, na perspectiva do autor, o processo de trabalho, quando acontece como consumo da força de trabalho pelo capitalista, apresenta dois fenômenos inseridos na dinâmica desse modo de produção, no qual ao capitalista pouco importa o conteúdo físico dos produtos do trabalho ou mesmo do processo dele, pois o que vale essencialmente é a quantidade de valor excedente encerrado em cada mercadoria produzida.

Nesse contexto, o trabalhador trabalha sob o controle do capitalista, a quem pertence o seu trabalho. Além disso, o produto é propriedade do capitalista, não do produtor imediato, o trabalhador. 0 processo de trabalho, assim como 0 produto do mesmo são separados da atividade própria do trabalhador, pertence a outrem, notadamente a outra classe social, e essa se configura na contradição fundamental da sociedade capitalista.

Significa dizer que na sociabilidade capitalista, o trabalho enquanto relação humana com a natureza, produtor de coisa útil, valor de uso, portanto trabalho concreto é subsumido à forma capitalista de trabalho, produtora de valor ou valor de troca, mais ainda de mais-valia.

Paulo Sergio Tumolo (1998) contribui com essa leitura, buscando avançar com radicalidade na inclusão da categorização fundamental sobre o trabalho 
produtivo. Para o autor, faz-se necessário concordar com a fundamentação de Ricardo Antunes (2006), segundo a qual o capitalismo é uma sociedade produtora de mercadorias e, por isso, o trabalho concreto está subsumido pelo trabalho abstrato. Para Tumolo é ainda forçoso reconhecer que esse modo de produção é essencialmente uma sociedade produtora de mais-valia e, por esta razão, o trabalho concreto (valor de uso) está subsumido pelo trabalho abstrato (valor), que, por sua vez, está subsumido pelo trabalho produtivo (mais-valia). Ressalta este autor que a produção de mais-valia é a razão última desse modo de produção, e por isso o trabalho produtivo determina tanto o trabalho abstrato como 0 trabalho concreto.

A leitura desses autores retoma diretamente as análises de Marx para pensar o trabalho na sociabilidade capitalista contemporânea. Para nossa reflexão sobre a constituição da categoria trabalho ou trabalhador produtivo, nos valeremos da noção de "trabalhador coletivo", apresentada por Marx em 0 Capital. Para o autor, a conceituação dessa forma de trabalho e seu executor se amplia em virtude do caráter cooperativo do processo de trabalho: "para trabalhar produtivamente não é mais necessário executar uma tarefa de manipulação do objeto de trabalho, basta ser órgão do trabalhador coletivo, exercendo qualquer uma das suas funções fracionárias" (MARX, 2003, p. 577).

Essa compreensão se faz fundamental para entendermos as transformações do trabalho na contemporaneidade em um campo geral de trabalho produtivo. Nessa perspectiva, inserem-se distintas formas de trabalho que, ao observá-las apenas de forma singular, não poderiam ser consideradas produtivas e, se inseridas na cadeia coletiva de produção, pode-se constatar sua face lucrativa, igualmente participante do enredo da apropriação do trabalho excedente realizado no interior da jornada de trabalho que, por muitas vezes, é prolongada ao limite máximo da fisiologia humana.

Também é fulcral atentarmos para as formas de trabalho que não materializam em si um produto físico, materialmente palpável. Nesse caso, esclarece-nos Harry Braverman (1981), podemos ter dificuldades ao pretender classificar estritamente o trabalho na sociedade capitalista com base em sua forma determinada. Informa o autor que para o capitalismo o que importa não é determinada forma de trabalho, mas sua forma social5 ${ }^{5}$, sua capacidade de

${ }^{5} \mathrm{Na}$ história do capitalismo, a tendência é no sentido da erradicação de distinções entre as
variadas formas de trabalho. Sobretudo, na era do capitalismo monopolista, faz pouco sentido
basear qualquer teoria econômica em qualquer variedade privilegiada especialmente de 
produzir, como trabalho assalariado, um lucro para o capitalista, sejam em bens ou serviços.

Nesta última caracterização, recorrentemente, encontra-se o trabalho feminino e por isso, ainda nos é fundamental tomar a perspectiva apontada por Hirata (1998) acerca da dimensão sexuada do trabalho. A perspectiva exposta pela autora serve, neste momento, como exemplo da postura metodológica que procuramos adotar, no sentido de nos empenharmos em uma análise dialéticomaterialista que, de acordo com Gaudêncio Frigotto (2009), deve procurar não se afastar dos fundamentos dessa teoria, assim como buscar saturar as categorias e conceitos no movimento mais universal do sistema do capital e na especificidade de diferentes formações histórico-sociais.

Concordar com essa assertiva significa posicionar-se em contrariedade ao abandono das categorias do materialismo histórico e buscar a citada saturação conceitual em relação à dimensão sexuada do trabalho, na convergência de reflexões de autoras como Helena Hirata e Denièle Kergoat, entre outras.

A estrutura teórica desenvolvida por estas autoras parte de uma reflexão crítica e subversiva no campo dos estudos do trabalho, que aprofunda a consideração da divisão sexual do trabalho, assim como das relações sociais de sexo, num esforço de "pensar o conjunto do social de maneira particular, porém não fragmentada.” (KERGOAT, 1997, p. 33).

A reflexão das autoras possui densa referência no marxismo o que, segundo as mesmas, é uma das diferenciações mais fortes entre o feminismo francês - do qual elas fazem parte - e o feminismo anglo-saxão, em particular o americano (HIRATA; KERGOAT, 1994). Essa referência realizada de maneira crítica avançou de forma definitiva no entendimento da complexidade da sociedade de classes.

0 impacto dessas teorizações se deu pelo fato de que, na tradição acadêmica, as classes sociais sempre foram tratadas como se a dimensão sexuada não implicasse nenhuma heterogeneidade na sua composição. Tais teorias afirmaram as relações de classe e as relaç̧ões de sexo como relações estruturantes e fundamentais da sociedade, em oposição a outras que são contingentes.

0 esforço descrito por Kergoat (1987) se refere à construção de novos instrumentos ou conceitos, ou à reapropriação original de antigos, para dar conta

processo de trabalho. À medida que essas formas variadas caem sob os auspícios do capital e se tornam parte do domínio de investimento lucrativo, entram para o capitalista no reino do trabalho geral ou abstrato, trabalho que amplia o capital (BRAVERMAN, 1981, p. 308). 
da compreensão da essência mesma das relações sociais em seu dinamismo. Retomando conceitos marxistas fundamentais, as autoras desenvolvem a articulação das relações de classe e as sociais de sexo, apontando que a dinâmica de uma esfera possui efeito sobre a outra. As relações de classe e de sexo, segundo as autoras, organizam a totalidade das práticas sociais em qualquer lugar.

Trata-se, segundo Kergoat (1997), de tomar as relações sociais de sexo e a divisão sexual do trabalho como duas formas indissociáveis, componentes de um sistema que constitui um marco teórico de conjunto, que aparece enquanto uma aquisição do feminismo, oriundo da emergência das categorias de sexo como categorias sociais, que vieram a demonstrar os arquétipos de homens e mulheres não como produtos de um destino biológico e sim, antes de tudo, como construções sociais com uma base material.

Kergoat (2000) aponta que homens e mulheres não são uma coleção - ou duas coleções - de indivíduos biologicamente distintos. Eles formam dois grupos sociais que estão engajados em uma relação social específica: as relações sociais de sexo. Estas, como todas as relações sociais, têm uma base material, no caso 0 trabalho, e se exprimem através da divisão social do trabalho entre os sexos.

A divisão sexual do trabalho ${ }^{6}$ é a forma de divisão do trabalho social decorrente das relações sociais de sexo; esta forma é adaptada historicamente e a cada sociedade. Ela tem por características a destinação prioritária dos homens à esfera produtiva e das mulheres à esfera reprodutiva e, simultaneamente, a apreensão pelos homens das funções de forte valoração social. Esta forma de divisão social do trabalho tem dois princípios organizadores: o princípio de separação - existem trabalhos de homens e trabalhos de mulheres - e o princípio de hierarquização - um trabalho de homem "vale" mais do que um trabalho de mulher (KERGOAT, 2000).

\section{REESTRUTURAÇÃO PRODUTIVA E TRABALHO FEMININO}

A chamada crise do fordismo-keynesianismo pode ser considerada um marco histórico no contexto da sociedade capitalista. No intuito de sua recomposição, o sóciometabolismo do capital passa a realizar alterações de forma, como as reformas políticas impostas dos grandes centros às periferias do sistema, a

\footnotetext{
${ }^{6}$ Para um possível aprofundamento no debate acerca da utilização das categorias ou terminologia de gênero, sexo e patriarcado, ver Scott (1995), Gates (1985), Viana (2006a, 2006b), Kergoat (1989, 1996, 2003), Saffioti (1992, 2004).
} 
desregulamentação das operações monetárias e a fuga de capitais para valoração na esfera financeira, assim como a promoção de um expressivo reordenamento no mundo do trabalho, incitado a partir da massiva introdução de novas tecnologias na produção - processo aludido segundo a concepção adotada nesse estudo como reestruturação produtiva do capital. Essa nova ordem produtiva impõe grandes metamorfoses para o trabalho, o que acaba por imprimir novos traços à face da classe trabalhadora.

Nos anos oitenta vimos mudanças mais acentuadas. Em uma década de crescente avanço da tecnologização industrial, na qual a automação e a microeletrônica adentraram ao espaço fabril, "inserindo-se e desenvolvendo-se nas relações de trabalho e de produção do capital" (ANTUNES, 2006, p. 23). 0 taylorismo e o fordismo passaram a dividir espaço com outros processos produtivos, especialmente advindos da experiência japonesa - o toyotismo. Processos inovadores de trabalho emergem e buscam adequar a produção aos fundamentos recentes do mercado e, assim, formas como o cronômetro e a produção em série e de massa vão sendo substituídas pela produção, acumulação e especialização, mais flexíveis (ANTUNES, 2006).

No interior desse processo, cabe-nos incluir as importantes reflexões no campo da economia e sociologia do trabalho, que passam a considerar mais profundamente a dimensão da divisão sexual do trabalho nos processos mediadores do reordenamento do mundo do trabalho. Nesse contexto, são fundamentais as pesquisas que indicam as interfaces sexuadas no mundo do trabalho. Esses estudos nos permitem avançar "nas difíceis e absolutamente necessárias interações entre classe e gênero" (ANTUNES, 2005, p. 108).

Helena Hirata (2002) chama atenção para uma importante questão: nesse movimento de crise, reordenamento do mundo do trabalho e reestruturação produtiva, em oposição à rigidez da legislação trabalhista, desenvolve-se acentuadamente o emprego de um tipo de força de trabalho, caracterizada como flexível. Nesse caso, afirma a autora, força de trabalho flexível não significa outra coisa que não seja a fundamental utilização do trabalho feminino contratado em tempo parcial (HIRATA, 2002).

Hirata (2007) afirma que a chamada flexibilidade do emprego passou a ser obtida inicialmente pelo desenvolvimento do trabalho temporário, dos contratos por tempo determinado e da terceirização nos países desenvolvidos. Com o desenvolvimento dessa modalidade nos países do hemisfério sul, visualizou-se 0 crescimento do trabalho informal, com ausência da regulamentação das condições 
de trabalho e a rigidez do quadro legal. A flexibilidade, segundo Hirata, seria uma das principais dimensões buscadas pelas inovações tecnológicas e organizacionais implementadas na empresa.

Nesse escopo, a autora atenta para o fato de que tal flexibilidade do trabalho é precondicionada pela divisão sexual do trabalho, restando às mulheres o amplo recurso do trabalho flexível e do assalariamento diferenciado diante deles.

No interior dessas metamorfoses no mundo do trabalho, em que a emergência da reabsorção da força de trabalho feminino passa a ser notada, uma questão central é evocada pela autora. Refere-se à justificação social imposta pelos mercados de trabalho em relação às modalidades de flexibilização da força de trabalho feminina - leia-se precarização. Esta acaba sendo relevada pela dimensão familiar em que ideologicamente se anuncia "a lógica do salário complementar, a preeminência da condição de mães de família sobre a condição de trabalhadoras" (HIRATA, 2002, p. 229)7. É nesse sentido que se articulam as situações de opressão vivenciadas pela mulher trabalhadora na esfera reprodutiva e a acentuada exploração de sua força de trabalho no campo da produção.

A questão da complementaridade do salário feminino também remete a uma secundarização de sua força de trabalho. Laís Abramo (2007) discute esse assunto em termos do ideário da mulher como uma força de trabalho secundária. Abramo (2007) afirma que essa noção ideológica está contida tanto na teoria econômica como no imaginário empresarial e social em geral, assim como se encontra presente frequentemente no planejamento e na implementação de políticas públicas. Assevera a autora que essa concepção se estrutura no entorno da visão da família nuclear centrada no homem provedor e na mulher como responsável pelas atividades na esfera privadå

Nessa expectativa, a inserção feminina no mundo do trabalho aparece como um aspecto secundário no seu projeto de vida, como se possuísse um caráter extraordinário dada a impossibilidade de o homem ser centro dos proventos por algum motivo especial ou mesmo por sua ausência. "Em conseqüência disso

\footnotetext{
${ }^{7}$ Nogueira (2004) referenciada em Hirata, afirma o mesmo, ponderando que embora se saiba que hoje, para algumas famílias, essa premissa não seja mais verdadeira, pois os valores complementares percebidos pelos assalariamentos femininos são frequentemente imprescindíveis para o equilíbrio do orçamento familiar.

${ }^{8}$ Diversas instituições do chamado mercado de trabalho, tipicamente instauradas no pósguerra, têm fundamento nesta idéia, algumas delas existentes até hoje, entre as quais estão 0 salário mínimo e alguns sistemas de pensão e planos de saúde (ABRAMO, 2007).
} 
[... ] a inserção da mulher no mercado de trabalho, também por definição, seria uma inserção ocupacional complementar, eventual, instável. Numa palavra, secundária" (ABRAM0, 2007, p. 29).

As pesquisas de Abramo (2007), ao apontarem as tendências do trabalho femininonaAmericaLatinae refletiremsobre acitadaconcepçãodasecundarização, afirmam que se em algum momento essas imagens de complementaridade do trabalho feminino guardaram correspondência com a realidade, atualmente se encontram em fase de mudança acelerada. Tanto na concepção do masculino enquanto provedor primário, quanto na própria noção de complemento de renda, e ainda nos aspectos quantitativos da participação feminina e prolongamento de suas trajetórias profissionais, existem pesquisas demonstrando o contradito dessa concepção ideológica.

Nessa discussão, acrescentaríamos a argumentação de que a atribuiç̧ão à força de trabalho feminina da condição de complementaridade ou secundarização nãopoderia ter outro apelo senão o ideológico, em sentido clássico. Daísuautilização como recurso do capital na justificação de desigualdades de remuneração, acesso e permanência. Se o fundamento mais essencial do metabolismo capitalista se apresenta no contexto da mais-valia, não analisar as mediações do trabalho feminino nessa composição seria errôneo. No interior dessa dinâmica, parecenos impossível, ou pelo menos impreciso, afirmar alguma secundarização de qualquer força de trabalho, que em termos gerais compõem um todo complexo como elementos da égide do trabalho abstrato capitalista. Vimos no decorrer da história e continuaremos nos deparando com exemplos de absorção e exploração da força de trabalho feminina em distintas ocasiões, o que não nos parece ilustrar a recorrência do capital a um tipo de força de trabalho secundária.

Somamos ainda a situação do trabalho reprodutivo, encargo hegemonicamente feminino, nos termos de uma jornada laboral adicional. Muito embora as exceções não estejam descartadas em absoluto, a grande maioria das transformações no mundo trabalho e as consequentes idas e vindas da força de trabalho feminina foram acompanhadas de uma marcante permanência do trabalho reprodutivo sob a responsabilidade da mulher. Nesse sentido, Antunes (2005) indica que a mulher trabalhadora de forma geral realiza sua atividade de trabalho duplamente, dentro e fora de sua casa, ou dentro e fora de seu emprego.

E, ao fazê-lo, além da duplicidade do ato do trabalho, ela é duplamente explorada pelo capital: desde $\log 0$ por exercer, no espaço público, seu trabalho produtivo no âmbito fabril. Mas, no universo da vida privada, ela 
consome horas decisivas no trabalho doméstico, com o que possibilita (ao mesmo capital) a sua reprodução, nessa esfera do trabalho não-diretamente mercantil, em que se criam as condições indispensáveis para a reprodução da força de trabalho de seus maridos, filhos, filhas e de si própria. Sem essa esfera da reprodução não-diretamente mercantil as condições de reprodução do sistema de metabolismo social do capital estariam bastante comprometidas, se não inviabilizadas (ANTUNES, 2005, p. 109).

Acrescentando outros dados em nossa reflexão, Nogueira (2004), auxilianos na construção do quadro sobre o trabalho feminino - e masculino - no contexto de ascensão do neoliberalismo, afirmando que em relação ao emprego masculino houve estagnação ou mesmo regressão e, em relação ao emprego e trabalho feminino assalariado houve um crescimento acentuado. Paradoxalmente, continua a autora, essa inserção se traduz majoritariamente em áreas nas que predominam empregos precários como os trabalhos em tempo parcial, com maior intensificação, ou com jornadas mais prolongadas, com maior vulnerabilidade, com grande diferenciação salarial - em relação aos homens.

Nogueira (2004) apresenta como conclusão que as recentes metamorfoses do mundo do trabalho - dentre as quais a sua feminização é fator fundamental contribuem positivamente para 0 avanço no complexo processo de emancipação feminina, minimizando formas de dominação no espaço reprodutivo. Por outro lado, essas transformações apresentam a negatividade do agravo das condições de precarização da mulher trabalhadora, consequência do processo capitalista de incorporação do trabalho feminino. Nessa incorporação, as características femininas como a polivalência e a multiatividade, decorrentes das atividades na esfera privada, são marcas consonantes com as formas de exploração pelo capital. Importante destacar que, para esta autora, o avanço na direção da emancipação feminina nesse contexto só pode ser parcial, pois o salto para esse processo em sua forma total só pode estar dado na perspectiva da emancipação humana, horizonte histórico situado para além da sociabilidade capitalista.

Outra questão importante para nosso estudo se refere às conseqüências das novas tecnologias e as novas organizações industriais para o trabalho em geral. No entanto, essa expectativa apenas alcançará as repercussões mais ampliadas no mundo do trabalho, caso tomemos a dimensão da divisão sexual do trabalho como ponto fundamental de analise (HIRATA, 2002).

Em consonância com suas pesquisas, Hirata (2002) constata que as transformações nos paradigmas produtivo e gerencial não se fazem em uníssono 
e que, sobretudo, ao considerarmos a força de trabalho feminina ou as indústrias dos países subdesenvolvidos, verificaremos que o chamado taylorismo não acabou. 0 trabalho nos moldes desse padrão de acumulação supostamente pretérito permaneceu às mulheres mesmo depois de inaugurada a era da acumulação flexível.

Completa Hirata (1998) que a idéia de que os novos modelos produtivos eliminam a monotonia dos trabalhos e a repetitividade das tarefas é apenas parcialmente verdadeira e conserva maiores prejuízos às mulheres. 0 que ocorre é que muitos dos postos desse tipo, ocupados por mulheres, são normalmente eliminados pela informatização e pela introdução da automação flexível. Por outro lado, os trabalhos repetitivos, monótonos, assim como a imposição temporal, reaparecem sob novas formas na atualidade, persistindo sob o domínio feminino. Assim, indica-se que as perspectivas de requalificação do operariado para o trabalho demandam alterações prioritariamente aos homens.

Toledo (2005) narra que a opressão feminina se relaciona com uma lógica mais fundamental que determina todas as demais no presente modo de produção, qual seja, a necessidade de o capital se reproduzir continuamente. Dessa articulação, a autora resgata o emprego das novas tecnologias enquanto imerso nas relações de reprodução ampliada do capital e não em outro sentido, como 0 alivio da exploração da classe trabalhadora, ou o abrandamento das diferenças sexuais. Segundo a autora, quanto mais são empregadas tecnologias no processo produtivo, mais se agrava o controle sobre os trabalhadores e trabalhadoras e, nesse mecanismo, os setores mais discriminados - entre eles as mulheres - sofrem graus especiais de exploração de onde o capital intensifica a extração lucrativa.

Segundo Toledo, a conformação da qualificação da mulher trabalhadora nesse modo de produção está dada segundo os interesses da acumulação, guardando relação com a divisão sexual do trabalho, que se utiliza de dados histórico-culturais e os aprofunda no sentido da administração de sua reprodução ampliada. Esta carrega, por sua vez, correlação com a possibilidade do movimento do emprego e desemprego da classe trabalhadora. Numa situação de pleno emprego, afirma a autora, as bases dessas mazelas estariam corroídas9.

\footnotetext{
${ }^{9}$ Aqui encontramos consonância com a noção apresentada por Pena (1981) da relação do trabalho feminino com os movimentos do exército industrial de reserva, que disponibiliza força de trabalho subvalorizada e que, numa reflexão na amplitude da totalidade social, não realiza outra coisa que não mais-valia em suas distintas manifestações. Nesse contexto, a permanência da sociabilização pelo trabalho humano, diferenciado segundo os sexos, com distintas valorações, parece absolutamente adequada ao processo de acumulação capitalista.
} 
Desse quadro mais generalizado do contexto da reestruturação produtiva do capital e do trabalho feminino, passaremos brevemente por algumas situações regionais. Destacando de forma mais palpável o contexto brasileiro, Bruschini, Ricoldi e Mercado (2007), baseados em estatísticas oficiais, destacam algumas das principais tendências do trabalho das brasileiras nas duas regiões mais populosas do país - sudeste e nordeste - que nos servem de referência para a conjuntura nacional.

[A] inserção laboral das brasileiras [é] marcada por progressos e atrasos: de um lado, a intensidade e a constância do aumento da participação feminina no mercado de trabalho, que vem ocorrendo desde a metade dos anos 1970, de outro, o elevado desemprego das mulheres e a má qualidade do emprego feminino; de um lado, a conquista de bons postos e 0 acesso a carreiras e profissões de prestígio por parte de mulheres escolarizadas, de outro, o predomínio do trabalho feminino em atividades precárias e informais (BRUSCHINI; RICOLDI; MERCADO, 2007, p. 16).

Apontam os autores para a intensidade e constância do crescimento da atividade laboral feminina no período pesquisado (1995-2005). Afirmam que indicadores como a população economicamente ativa demonstram o aumento considerável da participação feminina, assim como as taxas de atividade e percentuais femininos no interior do conjunto dos trabalhadores.

Nesse contexto, um dos fatores que mais significativamente impactam na entrada das brasileiras no mercado de trabalho é a expansão de sua escolaridade. Segundo estes autores, a escolaridade das trabalhadoras é superior à dos trabalhadores, dado diferencial que também pode ser verificado na população em geral. A elevada escolaridade possui também impacto considerável no ingresso feminino no mercado, pois as taxas de atividade das trabalhadoras mais instruídas são muito mais elevadas que as taxas gerais de atividade.

Essa pesquisa aponta também que a inserção das mulheres no mercado de trabalho brasileiro se caracteriza, ao longo do tempo, pela precariedade que atinge importante parcela das trabalhadoras. Entretanto, em contraste com as ocupações precárias, mulheres instruídas, além de continuar marcando presença em tradicionais guetos feminizados - como magistério e enfermagem - vêm ocupando áreas profissionais de prestígio como a medicina, a advocacia, a engenharia, esta última, tradicional reduto masculinizado. Para os autores, essa poderia ser considerada uma das faces do progresso alcançado pelas mulheres no que tange à sua participação no mercado de trabalho. 
Hirata (2001/2002) descreve esse fenômeno nos termos de uma bipolarização do trabalho assalariado feminino, em que uma parcela diminuta da força de trabalho feminino estaria alocada em funções qualitativamente superiores e, num campo imediatamente oposto, repousaria um contingente maior.

A atividade feminina continua concentrada em setores como serviços pessoais, saúde e educação. Contudo, a tendência a uma diversificação das funções mostra hoje um quadro de bipolarização: num extremo, profissionais altamente qualificadas, com salários relativamente bons no conjunto da força de trabalho feminina (engenheiras, arquitetas, médicas, professoras, gerentes, advogadas, magistradas, juízas, etc.), e, no outro extremo, trabalhadoras ditas de "baixa qualificação", com baixos salários e tarefas sem reconhecimento nem valorização social. Essa bipolarização não surge apenas nos países europeus desenvolvidos, mas também em países semi-industrializados como o Brasil (HIRATA, 2001/2002, p. 148).

No Brasil, entre novas configurações e recentes processos de transformação no cenário do trabalho feminino, Bruschini, Ricoldi e Mercado (2007) e demais autores levam também em consideração as fundamentais persistências na caracterização desse tipo de força de trabalho. No que se referem à ocupação, os dados sinalizam que persistem os conhecidos padrões diferenciados da inserção feminina e masculina em determinados setores ou grupos de atividades econômicas.

Os setores do mercado nos quais as trabalhadoras continuam encontrando maiores oportunidades de trabalho e emprego são, pela ordem, prestação de serviços, agropecuária, setor social, comércio de mercadorias e indústria. A força de trabalho masculina, por outro lado, manteve presença significativa, também pela ordem, na indústria, nos trabalhos ligados à agropecuária, no comércio de mercadorias e na prestação de serviços pequenos (BRUSCHINI; RICOLDI; MERCAD0, 2007, p. 24).

Outro dado apresentado pelos autores marca bem a tendência à precarização das ocupações femininas. No ano de 2005, 33\% da força de trabalho feminina no Brasil, ou nada menos que doze milhões de trabalhadoras estavam em precários nichos como trabalhadoras domésticas, em atividades não-remuneradas ou trabalho na produção para o consumo próprio ou do grupo familiar.

0 emprego doméstico remunerado é o nicho ocupacional feminino por excelência, no qual mais de $90 \%$ dos trabalhadores são mulheres. Ele se manteve 
como importante fonte de ocupação, praticamente estável até 2005, absorvendo $17 \%$ da força de trabalho feminina no Brasil, $15 \%$ no nordeste e $19 \%$ no sudeste. A ocupação de trabalhadora doméstica ainda representa, nos dias de hoje, oportunidade de colocação para mais de 6 milhões de mulheres no mercado de trabalho brasileiro (BRUSCHINI; RICOLDI; MERCADO, 2007, p. 26).

A estrutura ocupacional apresenta tendências recorrentes nos últimos anos. No emprego formalizado, continua-se o padrão de ocupações das mulheres com elevada presença em setores tradicionais da indústria como as costureiras no ramo de confecções, "assim como nos serviços de cuidado pessoal, higiene, alimentação, como é o caso das cabeleireiras e especialistas em estética em geral, das faxineiras, arrumadeiras em domicílios e hotéis, lavadeiras, tintureiras e cozinheiras" (BRUSCHINI; RICOLDI; MERCADO, 2007, p. 28).

Persistem igualmente outros tradicionais guetosfemininos, comoenfermagem (89\% da ocupação feminina), nutrição (93\%), assistência social (91\%), psicologia (89\%) e magistério nos níveis pré-escolar (95\%), fundamental (88\%) e médio (74\%). A presença feminina continua predominante ainda entre as secretárias (85\%) e auxiliares de contabilidade e caixas (75\%). (BRUSCHINI; RICOLDI; MERCADO, 2007, p. 28).

Dessa forma, podemos visualizar mais especificamente onde se insere 0 trabalho feminino no contexto geral dasociedade. Ampliar o prisma para considerar a divisão sexual do trabalho, a nosso ver, aprofunda ainda mais a compreensão da configuração da sociedade de classes contemporânea, que apresenta ao mesmo tempo, transformações e estagnaç̧ões.

\section{CONSIDERAÇÕES FINAIS}

0 quadro exposto nas linhas anteriores alcança, a nosso ver, a caracterização do contexto no qual estão inseridas trabalhadoras e trabalhadores numa conjuntura de reestruturação produtiva do capital.

Em contraposição às teses que propugnam o fim do trabalho, a argumentação desenvolvida no decorrer do texto demonstra a atualidade da exploração do trabalho em distintas formas. Permanece não apenas o trabalho na sua forma contraditória, combinando por um lado o alto desenvolvimento das forças produtivas e, de outro, formas pretéritas de realização do trabalho, mas também se mantém a vitalidade do corpo categorial marxista acerca do labor e sociabilidade humana na compreensão radical do modo de produção capitalista. 
Compreender o trabalho e a classe trabalhadora na atualidade, a nosso ver, passa obrigatoriamente pela reflexão da dimensão sexuada do trabalho. Perspectiva de análise sem a qual a apreensão do real se apresenta de forma limitada, enfraquecida e adaptada a ordem do capital.

No contexto da reestruturação produtiva, a correlação de forças na economia política indica um amplo desfavorecimento da classe trabalhadora em relação ao capital (LIMA FILHO, 2004). Essa situação nos parece indicar um agravamento ainda maior da condição de alienação da face feminina da classe trabalhadora, visto que a situação de sua força laboral no mundo do trabalho tem sido caracterizada tendencialmente pela precarização e flexibilização.

\section{REFERÊNCIAS}

ABRAM0, Laís. Inserção das mulheres no mercado de trabalho na América Latina: uma força de trabalho secundária? In: HIRATA, Helena; SEGNINI, Liliana (Org.). Organização, trabalho e gênero. São Paulo: SENAC, 2007.

ANTUNES, Ricardo. Adeus ao trabalho? Ensaio sobre as metamorfoses e a centralidade do mundo do trabalho. São Paulo: Cortez, 2006.

Os sentidos do trabalbo: ensaio sobre a afirmação e a negação do trabalho. São Paulo: Boitempo, 2005.

BRUSCHINI, Cristina; RICOLDI, Arlene Martinez; MERCADO, Cristiano Miglioranza. Trabalho e gênero no Brasil até 2005: uma comparação regional. In: HIRATA, Helena; SEGNINI, Liliana (Org.). Organização, trabalho e gênero. São Paulo: SENAC, 2007.

BRAVERMAN, Harry. Trabalho e capital monopolista: a degradação do trabalho no século XX. 3. ed. Rio de Janeiro: Jorge Zahar, 1981.

FRIGOTTO, Gaudêncio. A polissemia da categoria trabalho e a batalhas das idéias nas sociedades de classe. Revista Brasileira de Educação, Rio de Janeiro, v. 14, n. 40, p. 168-194, 2009.

HIRATA, Helena. Flexibilidade, trabalho e gênero. In: HIRATA, Helena; SEGNINI, Liliana (Org.). Organização, trabalho e gênero. São Paulo: SENAC, 2007.

. Nova divisão sexual do trabalho? Um olhar voltado para a empresa e a sociedade. São Paulo: Boitempo, 2002. 
. Globalização e divisão sexual do trabalho. Cadernos Pagu, São Paulo, v. 17/18, p. 139-156, 2001/2002.

. Reestruturação produtiva, trabalho e relações de gênero. Revista Latino-americana de Estudos do Trabalho, São Paulo, ano 4, n. 7, p. 5-27, 1998. HIRATA, Helena; KERGOAT, Daniele. A classe operária tem dois sexos. Revista Estudos Feministas, Rio de Janeiro, v. 2, n. 3, 1994.

IASI, Mauro Luís. As metamorfoses da consciência de classe: o PT entre a negação e o consentimento. São Paulo: Expressão Popular, 2006.

KERGOAT, Denièle. Divisão sexual do trabalho e relações sociais de sexo. In: HIRATA, Helena et al. (Org.). Dictionnaire critique du féminisme. Paris: Ed. Presses Universitaires de France, 2000.

. A propósito de las relaciones sociales de sexo. In: HIRATA, Helena; KERGOAT, Danièle. La división sexual del trabajo: permanencia y cambio. Argentina: Associación Trabajo y Sociedad, 1997.

. Em defesa de uma sociologia das relações sociais. Da análise crítica das categorias dominantes à elaboração de uma nova conceituação. In: KARTCHEVSKY, A. et al. (Org.). O sexo do trabalbo. Rio de Janeiro: Paz e Terra, 1987.

LIMA FILHO, Domingos Leite. Dimensões e limites da globalização. Petrópolis. Vozes, 2004.

MARX, Karl. O capital. Crítica da economia política. Livro I. Rio de Janeiro: Civilização Brasileira, 2003.

NOGUEIRA, Claudia Mazzei. A feminização no mundo do trabalho: entre a emancipação e a precarização. Campinas: Autores Associados, 2004.

PENA, Maria Valéria Junho. Mulheres e trabalhadoras: presença feminina na constituição do sistema fabril. Rio de Janeiro: Paz e Terra, 1981.

SCOTT, Joan. Gênero: uma categoria útil de análise histórica. Educação e Realidade, Porto Alegre, v. 20, n. 2, p. 71-99, 1995.

TOLEDO, Cecília. Mulheres: o gênero nos une, a classe nos divide. São Paulo: Instituto José Luis e Rosa Sundermann, 2005.

TUMOLO, Paulo Sergio. Trabalho: categoria sociológica chave? A necessária continuidade da discussão. Revista Universidade e Sociedade, Brasília, v. 15, n. 15, p. 85-93, 1998. 